\title{
Complete blood count alterations in COVID-19 patients: A narrative review
}

\author{
Mariangela Palladino* \\ Emergency Department, Umberto I University Hospital, Rome, Italy \\ *Corresponding author: mariangelapalladino@tiscali.it
}

\begin{abstract}
Coronavirus disease 2019 (COVID-19) pandemic represents a scientific and social crisis. One of the main unmet needs for coronavirus disease 2019 is its unpredictable clinical course, which can rapidly change in an irreversible outcome. COVID-19 patients can be classified into mild, moderate, and severe. Several haematological parameters, such as platelets, white blood cell total count, lymphocytes, neutrophils, (together with neutrophillymphocyte and platelet-lymphocyte ratio), and haemoglobin were described to be associated with COVID-19 infection and severity. The purpose of these review is to describe the current state of the art about complete blood count alterations during COVID-19 infection, and to summarize the crucial role of some haematological parameters during the course of the disease. Decreased platelet, lymphocyte, haemoglobin, eosinophil, and basophil count, increased neutrophil count and neutrophil-lymphocyte and platelet-lymphocyte ratio have been associated with COVID-19 infection and a worse clinical outcome. Our study adds some novelty about the identification of effective biomarkers of progressive disease, and might be helpful for diagnosis, prevention of complications, and effective therapy.
\end{abstract}

Keywords: haematology; COVID-19 virus disease; critical care

\section{Introduction}

In December 2019, coronavirus disease 2019 (COVID-19) was firstly reported in Wuhan, China. The pathogenic agent was determined to be a novel b-coronavirus, which is currently named severe acute respiratory syndrome coronavirus 2 (SARSCoV-2) (1). Patients experience a spectrum of disease from a mild illness, through varying severity of pneumonia all the way to acute respiratory distress syndrome (ARDS) and sepsis with multi-organ failure and death. The majority of patients develop pneumonia, which can proceed in up to 20 $30 \%$ of cases to respiratory failure requiring intubation and ventilatory support (2). Because of the rapid spread of the COVID-19 pandemic, affected countries have taken a heterogeneous and evolving approach to the diagnosis of infection in patients, and continue to have different and, in some cases, evolving strategies to determine what seg- ments of the population should be tested. Currently, the gold standard for the diagnosis of COVID-19 patients is the detection of SARS-CoV-2 nucleic acid by real-time reverse transcription polymerase chain reaction (RT-PCR) in respiratory specimens (oro- and nasopharyngeal swabs, sputa, nasal aspirates and washes, bronchoalveolar lavage and lung tissue specimens collected at autopsy) (3). Based on studies conducted in China and elsewhere, the clinical haematology laboratory plays an important role by providing the clinical team a number of useful prognostic markers and might be an important partner in the triage and management of affected patients. Some laboratory abnormalities include the decreased white blood cell and lymphocyte count, neutrophilia, thrombocytopenia, increased C-reactive protein $(C R P)$, erythrocyte sedimentation rate (ESR), and 
abnormal procalcitonin (PCT) in most patients (4). In particular, the blood count of patients with COVID-19 infection at diagnosis shows alterations that correlate with the stage and severity of the disease (5).

Laboratory blood tests have not been assessed with regard to their sensitivity or specificity for the diagnosis of COVID-19, nor their value as prognostic indicators. This literature review summarizes the blood cell count variations and their clinical significance in COVID-19 patients, having the purpose to gain an understanding of the existing data about haematological alterations occurring in COVID-19 infection, and debating particular prognostic markers which may be useful to stratify patients at the early diagnosis and eventually provide prompt treatment.

\section{Literature search}

A literature search was performed using the PubMed and Google Scholar databases to identify studies on haematological findings of COVID-19 up to April 2021. The keywords used in the search were as follows: SARS-CoV-2, COVID-19, blood count, laboratory findings, and haematology. The initial selection was based on the article title and abstract, following which the full-text article was read. Inclusion criteria were any study or article that included information about laboratory alterations in SARS-CoV-2. All types of studies and countries of origin were eligible for inclusion. We excluded articles that exclusively reported data on coagulative parameters, or that did not relate to the clinical aspects of interest, and that were not written in the English language. The findings from primary research articles, reviews, case reports, and case series were summarized and discussed narratively. Our search retrieved 446 records, of which 253 were excluded via title and abstract screening. A total of 193 full articles were assessed for eligibility. Of these, 120 papers relating to blood cells and SARS-CoV-2 were identified, from which data were extracted and synthesized. Articles relevant to the topic were included in the reference lists, after removing duplicates.

\section{Platelets}

Platelet (PLT) count is an important parameter included in numerous classification systems that evaluate disease severity, such as in multiorgan dysfunction syndrome. In COVID-19 infection, the presence of thrombocytopenia correlates with the severity of the disease and indicates the presence of a consumption coagulopathy. Similar to published data on severe acute respiratory syndrome and Middle East respiratory syndrome infection, it is found in approximately $60 \%$ of severe patients (6). Lippi et al. correlated a low PLT count with higher mortality and more severe COVID-19 illness (7). Platelet number was found to be lower in patients with either more severe illness or poor outcomes and even lower in non-survivors. An interesting point of the subgroup analysis is that thrombocytopenia may not be significantly related to intensive care unit (ICU) admission. This aspect could be explained considering that thrombocytopenia tends to reach a significant level in the late clinical stage of COVID-19 (8).

The mechanism by which the coronavirus interferes with the haematopoietic system is still unclear. Three mechanisms of a cascade can be assumed to explain thrombocytopenia in SARSCoV-2 infections: 1) direct infection of bone marrow cells by the virus with inhibition of PLT synthesis; 2) destruction of PLTs by the immune system; 3) aggregation of PLTs in the lungs with the formation of microthrombi and further consumption of PLTs.

Viruses can interact with megakaryocytes and reduce PLT synthesis (9). It has been assumed that the SARS-CoV-2 inhibits bone marrow haematopoiesis through specific receptors to depress the primary formation of PLTs and resulting thrombocytopenia (10). Viral infection and inflammation result in pulmonary capillary damage. Damaged lung tissues and pulmonary endothelial cells may cause a process of megakaryocyte rupture and increased PLT consumption (11). Also, SARS-CoV-2 can boost autoantibodies and immune complexes, resulting in the specific destruction of PLTs by the immune system (12). While PLTs contribute to the basal barrier integrity of the alveolar capillar- 
ies, they may also contribute to lung injury in a variety of pulmonary disorders and syndromes (13). PLT-leukocyte aggregates and PLT-endothelial interactions appear to play a role in the pathogenesis of acute lung injury (14). In Covid-19 infection, the damage of the lung tissues and lung endothelial cells can cause PLT aggregations with the formation of micro thrombi and further consumption of PLTs (15). In fact, most patients with thrombocytopenia have high concentrations of D-dimers with alteration of the coagulation parameters that confirm the hypothesis of triggering intravascular coagulation (16).

The PLT count associated with the hypoxemia value has also been described as a predictive model of the severity of the disease, with an accuracy of $96 \%$ (17). Conversely, only a small fraction of patients have thrombocytosis (18). COVID-19 patients were found to have significantly larger mean platelet volume (MPV) than critically ill non-COVID-19 patients matched for PLT count (11.6 vs 10.5 $\mathrm{fL}, \mathrm{P}=0.013$ ). Moreover, there was a significant trend of elevated immature platelet fraction (IPF) in COVID-19 patients. COVID-19 positivity was highly predictive of an absolute IPF of $7.5 \times 10^{9} / \mathrm{L}$ or higher; also, COVID-19-positive patients had relative IPF $\geq 8 \%$ at PLT counts up to $251 \times 10^{\%} / \mathrm{L}$. In contrast, in the non-COVID-19 patients, a relative IPF of $\geq 8 \%$ was restricted to those with PLT counts less than $70 \times 10^{9} / \mathrm{L}$ (19). These findings suggest that COVID-19 is associated with the increased production of large immature PLTs, as megakaryocytes respond to increased PLT consumption.

\section{White blood cells}

\section{Lymphocytes}

The best recognized haematological abnormality in patients affected by COVID-19 infection is lymphopenia, which is seen in up to $85 \%$ of severe cases with the severity of lymphopenia linked to outcome (20). The presence of lymphopenia (defined by an absolute number of lymphocytes $<1.0$ $\mathrm{x} 10^{9} / \mathrm{L}$ ) is reported in most of the published series and is commonly considered to be a deficient immunological response to viral infection (21).
Since the SARS-CoV-2 was identified, this novel virus began to be compared to influenza. Of respiratory infections, influenza is the most well studied viral infection and is commonly reported as the cause of epidemics. The lymphocyte count of the severe COVID-19 group was found to be significantly lower than in the common COVID-19 and influenza groups $(P<0.001$ and $P=0.012)$. Common cases of Covid-19 infection were defined as those who had a fever, respiratory tract symptoms, and pneumonia on imaging. Severe cases were those who had one of the following three clinical manifestations: (a) shortness of breath with a respiratory rate greater than 30 breaths/min, (b) mean oxygen saturation $\leq 93 \%$ in the resting state, and (c) partial pressure of arterial oxygen/oxygen concentration $\leq 300 \mathrm{mmHg}$. Severe cases also included the progress of lesions by more than $50 \%$ within 24 to 48 hours, as detected by pulmonary imaging. All influenza cases were confirmed by RT-PCR assay of nasal and pharyngeal swab specimens. Lymphocytes percentage rate of influenza and severe COVID-19 groups were significantly lower than in the common COVID-19 group $(P<0.001)$ (22). In a cohort of 120 COVID-19 patients, 100 influenza patients, and 61 healthy controls, lower lymphocytes were found in COVID-19 and influenza groups compared to healthy controls (23). However, distinct subpopulations of CD8+ T cells might be involved in COVID-19 and influenza. When analysing disease-specific transcriptional signatures in CD8+ T cells, the authors found that biological pathways for responses to interferon (IFN)-I and -II were more associated with the influenza-specific cellular cluster, whereas pathways for the response to tumour necrosis factor (TNF) or interleukin-1 $\beta$ (IL-1 $\beta$ ) were more prominent in COVID-19-specific clusters (24). In summary, COVID-19 and influenza can cause different changes in peripheral blood parameters, which should be considered in the early stages of COVID-19 and influenza.

It is well known that alteration in total lymphocyte numbers and the subsets varies with different virus types, indicating a potential association between lymphocyte subset alteration and viral pathogenic mechanisms (25). Lymphopenia might be caused by virus attachment or indirectly by im- 
mune injuries from inflammatory mediators. Moreover, exudation of circulating lymphocytes into inflammatory lung tissues might also lead to lymphopenia. The reduction of lymphocyte subset count in COVID-19 patients was investigated across 20 peer-reviewed studies for reporting lymphocyte subset counts and COVID-19 disease severity. $C D 4+T$ cell, $C D 8+T$ cell, $B$ cell, Natural killer (NK) cell, and total lymphocyte cell counts all showed a statistically significant reduction in patients with severe/critical COVID-19 disease compared to mild/moderate disease (26). The results remained consistent despite the differences in the definition of disease severity across the studies (27-29). Counts of total, CD4+, or CD8+ T cells lower than 800,400 , or $300 / \mu \mathrm{L}$, respectively, were negatively correlated with the patient outcome; the counts of the total, CD4+, and CD8+ T cells, importantly, were significantly lower in ICU patients than non-ICU cases. Further, an age-dependent reduction of $\mathrm{T}$ cell numbers was observed, with the lowest $T$ cells numbers found in patients $\geq 60$ years old, thus suggesting a potential cause for increased susceptibility in elderly patients (27). No significant difference was observed in CD4+/CD8+ ratio and NK cells in severe cases compared with mild illness (28), (Table 1). Total lymphocytes, CD4+, and CD8+ T cells were also found to inversely correlate with inflammatory indicators as ESR and CRP, while CD4+/CD8+ ratio was directly correlated with ESR and CRP (28). However, the expression of cell surface and intracellular molecules is not detectable by routine automated cell counter but needs to be analysed by flow cytometry.

Along with the severity of COVID-19 disease, a progressive $\mathrm{T}$ cell exhaustion, mediated by the expression of some immune-inhibitory molecules, has been evidenced during the course of infection (30). It is well known that persistent stimulation by the virus may induce $T$ cell exhaustion, leading to loss of cytokine production and cellular dysfunction (31). On the other hand, efficacious therapy with chloroquine was accompanied by an increased number of T cells and NK cells. Therefore, it might be hypothesized that in COVID-19 patients with severe pulmonary inflammation, SARS-CoV-2 correlates with functional exhaustion of cytotoxic lymphocytes at the early stage, which may result in disease (29). A low T cells count, an increase in naïve helper $T$ cells, and a decrease in memory helper T cells were found in patients severely affected by COVID-19 (32). Moreover, a lower level of regulatory $T$ cells has been found in severe cases (20). Reconstitution of lymphocytes may be an important factor for recovery (33). Low lymphocyte count might be used by clinicians in risk stratification to predict severe and fatal COVID-19 in hospitalized patient.

TABLE 1. Findings for CD4+, CD8+, CD4+/CD8+ ratio, NK cells variations in severe/critical COVID-19 disease compared to mild/moderate disease

\begin{tabular}{|c|c|c|c|c|c|c|c|c|}
\hline $\begin{array}{l}\text { First Author (Country) } \\
\text { (Reference number) }\end{array}$ & $\begin{array}{l}\text { Sample } \\
\text { size (N) }\end{array}$ & $\begin{array}{c}\text { Total } \\
\text { lymphocytes } \\
\text { (P-value) }\end{array}$ & $\begin{array}{c}\text { T cells } \\
\text { (P-value) }\end{array}$ & $\begin{array}{c}\text { CD4+ } \\
\text { cells } \\
\text { (P-value) }\end{array}$ & $\begin{array}{l}\text { CD8+ cells } \\
\text { (P-value) }\end{array}$ & $\begin{array}{c}\text { CD4+/ } \\
\text { CD8+ ratio } \\
\text { (P-value) }\end{array}$ & $\begin{array}{l}\text { NK cells } \\
\text { (P-value) }\end{array}$ & $\begin{array}{c}\text { B cells } \\
\text { (P-value) }\end{array}$ \\
\hline $\begin{array}{c}\text { Huang et al. (USA) } \\
(26)\end{array}$ & 3017 & $\begin{array}{c}\text { decreased } \\
(<0.001)\end{array}$ & n.a. & $\begin{array}{c}\text { decreased } \\
(<0.001)\end{array}$ & $\begin{array}{l}\text { decreased } \\
(<0.001)\end{array}$ & n.a. & $\begin{array}{c}\text { decreased } \\
(<0.001)\end{array}$ & $\begin{array}{c}\text { decreased } \\
(<0.001)\end{array}$ \\
\hline $\begin{array}{c}\text { Diao et al. (China) } \\
(27)\end{array}$ & 522 & n.a. & $\begin{array}{c}\text { decreased } \\
(<0.01)\end{array}$ & $\begin{array}{c}\text { decreased } \\
(<0.01)\end{array}$ & $\begin{array}{c}\text { decreased } \\
(<0.01)\end{array}$ & n.a. & n.a. & n.a. \\
\hline $\begin{array}{c}\text { Wang et al. (China) } \\
\text { (28) }\end{array}$ & 60 & $\begin{array}{l}\text { decreased } \\
(<0.001)\end{array}$ & n.a. & $\begin{array}{c}\text { decreased } \\
(0.024)\end{array}$ & $\begin{array}{c}\text { decreased } \\
(0.005)\end{array}$ & $\begin{array}{c}\text { no } \\
\text { difference } \\
(0.392)\end{array}$ & $\begin{array}{c}\text { no } \\
\text { difference } \\
(0.177)\end{array}$ & $\begin{array}{l}\text { decreased } \\
(0.018)\end{array}$ \\
\hline $\begin{array}{l}\text { Zheng et al. (China) } \\
\text { (29) }\end{array}$ & 68 & n.a. & $\begin{array}{c}\text { decreased } \\
(<0.05)\end{array}$ & n.a & $\begin{array}{c}\text { decreased } \\
(<0.05)\end{array}$ & n.a & $\begin{array}{c}\text { decreased } \\
(<0.05)\end{array}$ & n.a. \\
\hline
\end{tabular}

n.a. - not available. NK - Natural killer cell. COVID-19 - coronavirus disease 2019. 


\section{Neutrophils}

Neutrophilia, except for patients with bacterial infections or superinfections, correlates with hyperinflammatory state and cytokine storm, an integral part of the pathogenic mechanism of COVID-19. Neutrophils are involved in many viral respiratory diseases associated with ARDS (34). A minority of patients present leucocytosis, supported by neutrophilia: this finding seems to correlate with a more severe course (35). As COVID-19 progresses, the number of circulating neutrophils gradually increases; thus, neutrophilia has been identified as a marker of severe respiratory disease and a poor outcome (36). Leukocytes and neutrophils were significantly higher in severe than in non-severe COVID-19 infected patients. Further, along with COVID-19 disease progression, both leukocyte and neutrophil counts increased in the severe groups (37).

In peripheral blood smear, morphological alterations in circulating neutrophils, such as the reduction of nuclear lobularity and the presence of heavy cytoplasmic granulations, have been described (38). These morphological changes were transient and reversible preceding the appearance of the large reactive atypical lymphocytes, characteristic of viral infections (39).

The increase of neutrophils has been reported not only in the bloodstream but also in the lung tissue (40). The increased infiltration of immature and/or dysfunctional neutrophil contributes to the abnormal lungs' immune response in severe patients. Similar to other viral infections, SARS-CoV-2 infection promotes neutrophil extracellular traps release, which can contribute to tissue damage. Aberrant activation of neutrophils might exacerbate host response in COVID-19. Lung autopsies revealed the presence of neutrophils in lung capillaries and their extravasation into alveolar space (41). Neutrophils have a crucial role as drivers of hyperinflammation associated with COVID-19 disease via enhanced degranulation and cytokine production (42). On the day of hospital admission, the median neutrophil count in severe COVID-19 patients was found higher than in the moderate and mild groups. Further, an increase in neutrophil count from day 7 to day 9 after symptom onset was evidenced. Given the relationship between neutrophilia and poor outcomes, it has been proposed that the change in neutrophil counts in peripheral blood or tissues might be strictly associated with lung damage in COVID-19 patients (43). Confirmation of these findings might lead to targeting neutrophils and their recruitment mediators to reduce the severity of COVID-19.

\section{Neutrophil-lymphocyte and platelet-lymphocyte ratio}

The neutrophil-lymphocyte ratio (NLR: absolute neutrophil count/absolute lymphocyte count) and platelet-lymphocyte ratio (PLR: absolute platelet count/absolute lymphocyte count) have been reported to be useful in the diagnosis, follow-up, and survey of various systemic inflammatory processes, such as cholangiocarcinoma, ischemic heart disease, acute pancreatitis, and as a prognostic marker of malignant tumours (44-47).

Neutrophil-lymphocyte ratio is elevated in the bloodstream of COVID-19 infected patients; Zhang et al. reported that NLR combined with IgG might be a better predictor than neutrophil count alone in predicting the severity of COVID-19 (48). Levels of NLR and PLR correlate with COVID-19 disease severity. Patients with severe disease had higher NLR and PLR values compared to non-severe diseases (49). Neutrophil-lymphocyte ratio and PLR have been considered independent factors associated with COVID-19 progression; however, the mechanisms behind this are not understood (50). At the early stage of COVID-19, the total number of leukocytes in peripheral blood is normal or decreases, while the lymphocyte count decreases (51). The initial and peak value of NLR in deceased patients were higher than in survivors $(P<0.001)(52)$. The increase of NLR means the progressive increase of neutrophils, and/or the decrease of lymphocytes. The increase of neutrophils often suggests an underlying bacterial infection, while the decrease of lymphocytes means a compromised system (53). Those suggest that it is necessary to pay attention to the COVID-19 patients with increased NLR (52). Worse outcomes were noted in patients presenting with a peak in the platelet count during the disease 
course, and the PLR at the time of platelet peak was identified as an independent prognostic factor for prolonged hospitalization (54). A case report describes NLR and PLR fluctuation during the progression of COVID-19 disease. From the admission, white blood cells, neutrophils, platelets, and the NLR gradually increased and reached a peak on the $14^{\text {th }}$ day, the PLR reached a peak on the $9^{\text {th }}$ day, while the number of lymphocytes did not reach the maximum value, but it showed only an upward trend. The NLR and the PLR gradually returned to normal after the patient's improvement on the $14^{\text {th }}$ day (55). In COVID-19 patients, the levels of new serological biomarkers, including NLR and PLR, were elevated in the severe disease group compared to those in mild to moderate patients (56). In a different study, no statistically significant difference was observed between COVID-19 negative and positive patients, respectively, regarding lymphocyte and PLR values $(P=0.081)$, while a statistically significant difference $(P<0.001)$ was found between the test groups regarding NLR values (57).

In COVID-19 patients, increased ferritin and PLR were found to be independent predictors of the disease severity (58). SARS-CoV-2-triggered hyperinflammation seems to increase PLR, which promotes severe prognosis. Studies suggested that PLR was linked to inflammation and could predict mortality among haemodialysis patients (59). Neutrophil-lymphocyte ratio and PLR are easily obtained from a serum complete blood count with a differential profile. They serve as a function of relative neutrophilia, thrombocytosis, and lymphopenia. While many inflammatory markers like CRP, ESR, lactate dehydrogenase, ferritin, and PCT are frequently measured in COVID-19 patients, NLR and PLR can be easily calculated using the differential count and are cost-effective especially for many third world countries. Monitoring the predictors of severity may assist clinicians to identify and followup patients with a higher risk for progression.

\section{Monocytes}

Monocytes constitute about 5-9\% of the total peripheral leukocytes, remain in the circulation for 1-2 days, following which these cells may differentiate to tissue-resident macrophages (60). SARS-CoV2 in- fects CD14+ monocytes through angiotensin-converting enzyme (ACE2), but viral replication in these cells is usually low or undetectable $(61,62)$. Anyway, the SARS-CoV-2-infected monocytes can produce large amounts of inflammatory mediators that support COVID-19-associated cytokine storm (63). Wen et al. revealed a predominant subset of CD14++IL1 $\beta+$ monocytes in patients in the early recovery stage of COVID-19 (64). Zhang D et al. did not detect significant differences in the absolute number of monocytes between patients with COVID-19 and normal healthy individuals but identified an increased proportion of activated monocytes/ macrophages in patients with COVID-19, and significant morphological and functional differences, which are more pronounced in patients requiring prolonged hospitalization and ICU admission. In particular, the numbers of circulating classical monocytes (CD14++CD16-) decrease, but the numbers of intermediate (CD14++CD16+) and nonclassical (CD14+CD16++) monocytes increase in COVID-19 patients. Moreover, patients with COVID-19 have larger than normal monocytes, easily identified on forward scatter (FSC) analysis by routine flow cytometry, with the presence of a distinct population of monocytes with high FSC. These FSC-high monocytes are CD11b+, CD14+, CD16+, CD68+, CD80+, CD163+, CD206+ and secrete IL-6, IL-10, and TNF-alpha, consistent with an inflammatory phenotype. In contrast, patients with a high proportion of normal monocytes have a better prognosis with earlier recovery and discharge from the hospital. These findings appear to be relatively specific for COVID-19 as we have not seen a similar pattern in patients with other viral illnesses, such as H1N1 influenza and human immunodeficiency virus (HIV) (61). A significant expansion of populations of CD14+CD16+ monocytes producing IL-6 was observed in the peripheral blood of patients with COVID-19 in ICU compared with those patients who did not require ICU hospitalization. Moreover, monocytes from COVID-19 patients were found to be able to secrete granulocyte-macrophage colony-stimulating factor (GM-CSF) (65). As the monocyte is the pathogenic GM-CSF responsive cell that requires GM-CSF to promote tissue damage in both mouse and human, it has been suggested that the increasing number of GM-CSF+ 
monocytes and IL-6+ monocytes in the peripheral blood is responsible for inflammatory cytokine storms occurring in COVID-19 infection $(65,66)$. SARS-CoV-2 infection of monocytes, which acts as antigen presenting cells, directly impairs the antiviral adaptive immune responses. Thus, interfering with monocytes infection and subsequent activation of cytokine production and cytokine-mediated signalling pathways can also attenuate systemic hyperinflammation.

\section{Eosinophils}

The role of eosinophils in the coronavirus-19 disease is unknown. Physiologically, tissue-resident eosinophils are mainly represented in the gastrointestinal tract and in the lung, where they have regulatory functions in protective immunity, and organ growth and metabolism (67). In a population of 140 patients infected with SARS-CoV-2 in Wuhan, $53 \%$ of the patients had eosinopenia at admission (68). Mu et al. evidenced a significant eosinopenia in 72/95 SARS-CoV-2 patients $(P<$ 0.01 ). The absolute eosinophil count was 0.01 $\mathrm{x} 10^{9} / \mathrm{L}$ and the eosinophil percentage was $0.3 \%$. Moreover, eosinophil blood count progressively returned to normal together with clinical conditions improvement, while continued to decline for patients without clinical improvement (69). In a retrospective analysis by Tan et al., decreased eosinophils were detected in 33 out of 40 patients with COVID-19 on admission, while eosinophils were inversely related to the severity of the disease, according to the Spearman's correlation coefficient $\left(r_{s}=-0.462 ; \mathrm{P}=0.003\right)$. Furthermore, the patients' peripheral blood eosinophils returned to normal values before the discharge, suggesting a putative role of eosinophils in predicting the prognosis of the patient (70).

Eosinopenia as a response to infection was first described in Zappert (71). The pathophysiology for eosinopenia in COVID-19 remains unclear but is likely multifactorial and related to the migration of eosinophils to the inflammatory site, inhibition of eosinophil mobilization from the bone marrow, blockade of eosinophilopoiesis, reduced expression of chemokine receptors/adhesion molecules, and/or direct eosinophil apoptosis induced by
IFN-I released during the acute phase of inflammation $(72,73)$.

\section{Basophils}

In-vivo, basophils leave the circulation and migrate to inflammatory sites during allergic inflammation and infection, enhancing immunological memory responses by binding antigens on their surface (74). Secretion of $\lg M$ or a class switch to $\lg G$ or $\lg A$ by $B$ cells is enhanced by activated basophils (75).

Rodriguez et al. demonstrated that basophils are depleted during acute and severe COVID-19, thus suggesting that the degree of basophil depletion may influence the efficacy of IgG responses to SARS-CoV-2 (76). Lower basophils were found in COVID-19 and influenza groups compared to healthy controls (77). Li et al. found that in the early stages of the disease, basophils counts were lower in COVID-19 patients than in controls (78). It is known that both basophils and eosinophils can produce IL-4, which is an important cytokine to stimulate the proliferation of activated $B$ and $T$ cells (79). Therefore, the decrease of basophil and eosinophil counts in COVID-19 patients may further explain the decrease of lymphocyte count. In a cohort of 452 patients affected by severe COVID-19 disease, higher leukocyte, and neutrophil counts and a lower percentage of basophils were found (20). Interestingly, low basophil counts were associated with viral infections in immunocompromised patients (80). On the other hand, it has been demonstrated that several HIV proteins can interact with different surface receptors on human basophils; also, HIV-infected basophils were found in the peripheral blood of acquired immunodeficiency syndrome patients $(81,82)$. Based on these considerations, a mechanism of viral encapsulation in basophils might be postulated as one possible explanation of low basophil count in patients affected by COVID-19 infection.

\section{Red blood cells and haemoglobin}

A significant impact of SARS-Co-V2-infection on red blood cell (RBC) structural membrane homeostasis at the protein and lipid levels was demonstrated. RBCs from COVID-19 patients had in- 
creased levels of glycolytic intermediates, accompanied by oxidation and fragmentation of membrane proteins. Thus, COVID-19 impacts two critical mechanisms that finely tune red cell membranes and haemoglobin oxygen affinity. RBCs from COVID-19 patients may be incapable of responding to environmental variations in haemoglobin oxygen saturation when traveling from the lungs to the bloodstream and, as such, may have a compromised capacity to transport and deliver oxygen (83). COVID-19 patients show higher levels of nitric oxide (NO) inside RBC compared to nonCOVID-19 hypoxemic patients, but the mechanism(s) causing the accumulation of intracellular NO in RBC of COVID-19 patients is still unclear (84). Autoimmune haemolytic anaemia (AIHA) was recently described in COVID-19 patients (85). Autoimmune haemolytic anaemia causes platelet cell death and RBCs can also modulate platelet activity through either chemical signalling or direct RBC-platelet interactions. Thus, evidence for haemolysis may account for the microvascular coagulation seen in COVID-19 patients. Berzuini et al. reported the observation that about half of patients with COVID-19 tested at their blood center had a positive direct antiglobulin test (DAT). However, eluates did not react with any test cells but did react with red cells from patients with COVID-19 that were DAT negative. This suggests that COVID-19 may modulate the red cell membrane and present novel antigenic epitopes (86).

Patients with COVID-19 present decreased haemoglobin concentration and pathologically increased concentrations of ferritin. Wang et al. reported reduced haemoglobin concentration $(<110 \mathrm{~g} / \mathrm{L})$ in $19 \%$ of the hospitalized patients (87); while Huang et al. reported reduction in haemoglobin concentrations in $38 \%$ of the study population admitted to the hospital (88). In this case, the higher incidence of a low haemoglobin concentration in COVID-19 patients described by Huang might be explained by the difference in age structure between the populations from the two studies. In fact, Huang et al. reported data from a population aged 56 (26-88), while the study population described by Wang et al. had a median age of 42 (3353). Haemoglobin concentration below $110 \mathrm{~g} / \mathrm{L}$ was associated with disease progression (89). On the other hand, Cai et al. discovered no associations between haemoglobin concentration and risk of admission at ICU (90). Taneri et al. analysed data from 189 studies and 57,563 COVID-19 patients across all ages, founding a pooled mean haemoglobin concentration of $129.7 \mathrm{~g} / \mathrm{L}$, which decreased with older age and a higher proportion of comorbid illness and disease severity. They also found increased values of ferritin in most patients, mainly in males, the elderly, and individuals with hypertension (91). Based on data from 54 observational studies, including 24,262 COVID-19 patients, pooled mean ferritin concentration in COVID-19 patients was $777.33 \mathrm{ng} / \mathrm{mL}$ Moreover, the mean difference in serum ferritin was higher in severe COVID-19 individuals compared to moderate cases. A linear trend with ferritin concentrations between severe and moderate COVID-19 cases increasing with advancing age was observed, while non-linear trends were observed between patients' characteristics and ferritin concentration among survivors and non-survivors. Odds in hospital death were higher among patients with ferritin above $300 \mathrm{ng} / \mathrm{mL}$ compared to those with serum ferritin $\leq 399 \mathrm{ng} / \mathrm{mL}$ (odds ratio $9.10[(95 \% \mathrm{Cl}$ 2.04 to $40.58, P=0.004]$ ). Concentrations of serum ferritin were elevated in non-survivors compared with survivors ( $562 \mathrm{ng} / \mathrm{mL}$ vs $492 \mathrm{ng} / \mathrm{mL}$ ) throughout the clinical course and were increased with disease deterioration (92). In another study, ferritin was significantly higher in severe cases (93). Both anaemia and hyperferritinemia, regardless of the underlying pathology, are associated with increased mortality (94). Haemoglobin concentrations were found lower with older age, a higher percentage of subjects with diabetes, hypertension, and overall comorbidities, and admitted to intensive care. Ferritin concentration increased with older age, increasing proportion of hypertensive study participants, and increasing proportion of mortality. Compared to moderate cases, severe COVID-19 cases had lower haemoglobin and RBC and higher ferritin and red cell distribution width (RDW) (95).

Anaemia could be the result of a sideroblastic-like anaemia pattern arising from alterations in iron 
metabolism, while increased ferritin could be indicative of a strong inflammatory reaction in COVID-19 or related to viral entry into the human body and its impact on iron metabolism. Functional iron deficiency was associated with significantly poorer clinical conditions and a longer hospital stay but was not linked to an increased risk of in-hospital death, ICU admission, or the need for mechanical ventilation. No significant relations were found between mortality rate and elevated ferritin concentrations. However, elevated ferritin concentrations were associated with longer hospital stays and increased risk for ICU admission and the need for mechanical ventilation (96). In COVID-19 infection, inflammation is related to iron metabolism biomarkers, and haemoglobin. Anaemic patients had significantly higher CRP, IL-6 and PCT levels. Accordingly, haemoglobin concentrations were only significantly correlated with CRP and tended to be related to IL-6, and PCT concentrations. In addition, patients with functional iron deficiency had significantly higher CRP, IL-6, and PCT concentrations when compared to patients with absolute iron deficiency or no iron deficiency. Accordingly, ferritin positively correlated with CRP, IL-6, and PCT concentrations. Taken together, these data are in accordance with the association of altered iron homeostasis with more advanced inflammation, the latter promoting lung injury and respiratory failure (97). Nonetheless, both anaemia and inflammation-induced alterations of iron homeostasis are important clinical predictors for risk stratification of SARS-CoV-2-infected patients.

Severe acute respiratory syndrome coronavirus 2 was shown to interfere with haemoglobin at erythrocyte and bone marrow level; the new SARS-CoV2 attack to bone marrow erythroblasts (98). Moreover, studies evidence an increased RDW in patients with COVID-19, thus suggesting the existence of underlying erythroid myelodysplasia, as RDW is higher when immature cells are produced (99). It has been found that SARS-CoV-2 interacts through ACE2, CD147, CD26, and other receptors located on erythrocytes and/or blood cell precursors, thus causing viral endocytosis. Consequently, the virus would attack the heme on the 1-beta chain of haemoglobin, inducing haemolysis and forming a complex with the released heme, producing a quote of dysfunctional haemoglobin (100).

\section{Limitations of the study}

A large proportion of the primary research is based on Asian patients; therefore, further verification is needed in populations in other areas. Eventually, further investigations are needed to assess geographic variability among blood parameters. This is a review of the current scientific literature with no statistical outcome measures. Therefore, these results may not be generalizable to all populations. Finally, the rapidly evolving nature of COVID-19 and the continuous discovery of novel data are additional limitations of this article.

\section{Conclusions}

Coronavirus disease 2019 has prominent manifestations from the hematopoietic system. Common haematological abnormalities have been identified in COVID-19 patients. Since the early stage of the disease, not only the platelets and lymphocytes but also haemoglobin, eosinophils, and basophils present a marked decrease, associating with the disease severity and clinical outcome. At the moment, the kinetics of monocytes in COVID-19 infection is still undefined, as SARS-CoV-2 infection of monocytes seems to directly impair the anti-viral adaptive immune responses. Finally, an increase of neutrophils and the two markers NLR and PLR seem to correlate with progressive disease. Careful evaluation of laboratory indices at baseline and during the disease course can assist clinicians in formulating a tailored treatment approach and promptly provide intensive care to those who are in greater need.

This review has emphasized the importance of laboratory information in the management of COVID-19, further studies are worth describing the association between the dynamic haematological responses and the progression and outcome of the disease.

\section{Potential conflict of interest}

None declared. 


\section{References}

1. Zhu N, Zhang D, Wang W, Li X, Yang B, Song J, et al. A novel coronavirus from patients with pneumonia in China, 2019. N Engl J Med. 2020;382:727-33. 10.1056/NEJMoa2001017

2. Attaway $A H$, Scheraga RG, Bhimraj A, Biehl M, Hatipoğlu U. Severe covid-19 pneumonia: pathogenesis and clinical management. BMJ. 2021;372:n436. https://doi.org/10.1136/ bmj.n436

3. National Health Commission \& National Administration of Traditional Chinese Medicine. Diagnosis and Treatment Protocol for Novel Coronavirus Pneumonia (Trial Version 7). Chin Med J. 2020;133:1087-95. 10.1097/ CM9.0000000000000819

4. Wu Z, McGoogan JM. Characteristics of and Important Lessons From the Coronavirus Disease 2019 (COVID-19) Outbreak in China. Summary of a Report of 72314 Cases From the Chinese Center for Disease Control and Prevention. JAMA. 2020;323:1239-42. https://doi.org/10.1001/ jama.2020.2648

5. Soraya GV, Ulhaq ZS. Crucial laboratory parameters in COVID-19 diagnosis and prognosis: An updated meta-analysis. Med Clin (English Edition). 2020;155:143-51. https://doi. org/10.1016/j.medcli.2020.05.017

6. Arabi YM, Arifi AA, Balkhy $H H$, Najm H, Aldawood AS, Ghabashi $A$, et al. Clinical course and outcomes of critically ill patients with Middle East respiratory syndrome coronavirus infection. Ann Int Med. 2014;160:389-97. https://doi. org/10.7326/M13-2486

7. Lippi G, Plebani M, Henry BM. Thrombocytopenia is associated with severe coronavirus disease 2019 (COVID-19) infections: a meta-analysis. Clin Chim Acta. 2020;506:145-8. https://doi.org/10.1016/j.cca.2020.03.022

8. Zong $X, G u Y, Y u$ PH, Li Z, Wang Y. Thrombocytopenia Is Associated with COVID-19 Severity and Outcome: An Updated Meta-Analysis of 5637 Patients with Multiple Outcomes. Lab Med. 2021;52:10-5. https://doi.org/10.1093/labmed/ Imaa067

9. Seyoum M, Enawgaw B, Melku M. Human blood platelets and viruses: defense mechanism and role in the removal of viral pathogens. Thromb J. 2018;16:16. https://doi. org/10.1186/s12959-018-0170-8

10. Ropa J, Cooper S, Capitano ML, Van't Hof W, Broxmeyer HE. Human Hematopoietic Stem, Progenitor, and Immune Cells Respond Ex Vivo to SARS-CoV-2 Spike Protein. Stem Cell Rev Rep. 2021;17:253-65. https://doi.org/10.1007/s12015-02010056-z

11. Assinger A. Platelets and infection - an emerging role of platelets in viral infection. Front Immunol. 2014;5:649. https:// doi.org/10.3389/fimmu.2014.00649

12. Wool GD, Miller JL. The Impact of COVID-19 Disease on Platelets and Coagulation. Pathobiology. 2021;88:15-27. https://doi.org/10.1159/000512007

13. Weyrich AS, Zimmerman GA. Platelets in lung biology. Annu Rev Physiol. 2013;75:569-91. https://doi.org/10.1146/annurev-physiol-030212-183752

14. Morrell CN, Aggrey AA, Chapman LM, Modjeski KL. Emerging roles for platelets as immune and inflammatory cells.
Blood. 2014;123:2759-67. https://doi.org/10.1182/blood-2013-11-462432

15. Thachil J. What does monitoring platelet counts in $\mathrm{CO}$ VID-19 teach us? J Thromb Haemost. 2020;18:2071-2. https://doi.org/10.1111/jth.14879

16. Zaid Y, Puhm F, Allaeys I, Naya A, Oudghiri M, Khalki L, et al. Platelets Can Associate With SARS-CoV-2 RNA and Are Hyperactivated in COVID-19. Circ Res. 2020;127:1404-18. https://doi.org/10.1161/CIRCRESAHA.120.317703

17. Zou Z, Yang Y, Chen J, Xin S, Zhang W, Zhou X, et al. Prognostic factors for severe acute respiratory syndrome: a clinical analysis of 165 cases. Clin Infect Dis. 2004;38:483-9. https:// doi.org/10.1086/380973

18. Al-Samkari H, Leaf RK, Dzik WH, Carlson JCT, Fogerty $A E$, Waheed A. COVID-19 and coagulation: bleeding and thrombotic manifestations of SARS-CoV-2 infection. Blood. 2020;136:489-500. https://doi.org/10.1182/blood.2020006520

19. Wool GD, Miller JL. The impact of Covid 19 Disease on platelets and coagulation. Pathobiology. 2021;88:15-27. https:// doi.org/10.1159/000512007

20. Qin C, Zhou L, Hu Z, Zhang S, Yang S, Tao Y, et al. Dysregulation of immune response in patients with COVID-19 in Wuhan, China. Clinical infectious diseases: an official publication of the Infectious Diseases Society of America 2020. Clin Infect Dis. 2020;71:762-8. https://doi.org/10.1093/cid/ ciaa248

21. van Wolfswinkel ME, Vliegenthart-Jongbloed $K$, de Mendonça Melo M, Wever PC, McCall MB, Koelewijn R, et al. Predictive value of lymphocytopenia and the neutrophil-lymphocyte count ratio for severe imported malaria. Malar J. 2013;12:101. https://doi.org/10.1186/1475-2875-12-101

22. Chen J, Pan Y, Li G, Xu W, Zhang L, Yuan S, et al. Distinguishing between COVID-19 and influenza during the early stages by measurement of peripheral blood parameters. J Med Virol. 2021;93:1029-37. https://doi.org/10.1002/jmv.26384

23. Kazancioglu S, Bastug A, Ozbay BO, Kemirtlek N, Bodur $H$. The role of haematological parameters in patients with COVID-19 and influenza virus infection. Epidemiol Infec. 2020;148:e272. https://doi.org/10.1017/ S095026882000271X

24. Lee JS, Park S, Jeong HW, Ahn JY, Choi SJ, Lee H, et al. Immunophenotyping of COVID-19 and influenza highlights the role of type I interferons in development of severe COVID-19. Sci Immunol. 2020;5:eabd1554. https://doi.org/10.1126/sciimmunol.abd1554

25. Li T, Qiu Z, Zhang L, Han Y, He W, Liu Z, et al. Significant changes of peripheral $T$ lymphocyte subsets in patients with severe acute respiratory syndrome. J Infect Dis. 2004;189:64851. https://doi.org/10.1086/381535

26. Huang W, Berube J, McNamara M, Saksena S, Hartman M, Arshad T, et al. Lymphocyte Subset Counts in COVID-19 Patients: A Meta-Analysis. Cytometry A. 2020;97:772-6. https:// doi.org/10.1002/cyto.a.24172

27. Diao B, Wang C, Tan Y, Chen X, Liu Y, Ning L, et al. Reduction and Functional Exhaustion of $T$ Cells in Patients 
with Coronavirus Disease 2019 (COVID-19). Front Immunol. 2020;11:827. https://doi.org/10.3389/fimmu.2020.00827

28. Wang F, Nie J, Wang H, Zhao Q, Xiong Y, Deng L, et al. Characteristics of Peripheral Lymphocyte Subset Alteration in COVID-19 Pneumonia. J Infect Dis. 2020;221:1762-9. https:// doi.org/10.1093/infdis/jiaa150

29. Zheng M, Gao Y, Wang G, Song G, Liu S, Sun D, et al. Functional exhaustion of antiviral lymphocytes in COVID-19 patients. Cell Mol Immunol. 2020;17:533-5. https://doi. org/10.1038/s41423-020-0402-2

30. Wherry EJ, Kurachi M. Molecular and cellular insights into $T$ cell exhaustion. Nat Rev Immunol. 2015;15:486-99. https:// doi.org/10.1038/nri3862

31. Ng CT, Snell LM, Brooks DG, Oldstone MB. Networking at the level of host immunity: immune cell interactions during persistent viral infections. Cell Host Microbe. 2013;13:652-64. https://doi.org/10.1016/j.chom.2013.05.014

32. Cossarizza A, De Biasi S, Guaraldi G, Girardis M, Mussini C, for the Modena Covid-19 Working Group (MoCo19). SARSCoV-2, the Virus that Causes COVID-19: Cytometry and the New Challenge for Global Health. Cytometry part A. 2020;97:340-3. https://doi.org/10.1002/cyto.a.24002

33. Henry BM, Benoit SW, Santos de Oliveira MH, Hsieh WC, Benoit J, Ballout RA, et al. Laboratory abnormalities in children with mild and severe coronavirus disease 2019 (COVID-19): A pooled analysis and review. Clin Biochem. 2020;81:1-8. https://doi.org/10.1016/j.clinbiochem.2020.05.012

34. Camp JV, Jonsson CB. A Role for Neutrophils in Viral Respiratory Disease. Front Immunol. 2017;8:550. https://doi. org/10.3389/fimmu.2017.00550

35. Yamada T, Wakabayashi M, Yamaji T, Chopra N, Mikami T, Miyashita H, Miyashita S. Value of leukocytosis and elevated C-reactive protein in predicting severe coronavirus 2019 (COVID-19): A systematic review and meta-analysis. Clin Chim Acta. 2020;509:235-43. https://doi.org/10.1016/j. cca.2020.06.008

36. Zhang L, Huang B, Xia H, Fan H, Zhu M, Zhu L, et al. Retrospective analysis of clinical features in 134 coronavirus disease 2019 cases. Epidemiol Infect. 2020;148:e199. https://doi. org/10.1017/S0950268820002010

37. Soraya GV, Ulhaq ZS. Crucial laboratory parameters in COVID-19 diagnosis and prognosis: An updated metaanalysis. Med Clin (Engl Ed). 2020;155:143-51. https://doi. org/10.1016/j.medcli.2020.05.017

38. Zini G, Bellesi S, Ramundo F, D'Onofrio G. Morphological anomalies of circulating blood cells in COVID-19. Am J Hematol. 2020;95:870-2. https://doi.org/10.1002/ajh.25824

39. Nazarullah A, Liang C, Villarreal A, Higgins RA, Mais DD. Peripheral Blood Examination Findings in SARS-CoV-2 Infection. Am J Clin Pathol. 2020;154:319-29. https://doi. org/10.1093/ajcp/aqaa108

40. Buja LM, WolfDA, Zhao B, Akkanti B, McDonald M, Lelenwa $L$, et al. The emerging spectrum of cardiopulmonary pathology of the coronavirus disease 2019 (COVID-19): Report of 3 autopsies from Houston, Texas, and review of autopsy findings from other United States cities. Cardiovasc Pathol. 2020;48:107233. https://doi.org/10.1016/j.carpath.2020.107233
41. Barnes BJ, Adrover JM, Baxter-Stoltzfus A, Borczuk A, Cools-Lartigue J, Crawford JM, et al. Targeting potential drivers of COVID-19: Neutrophil extracellular traps. J Exp Med. 2020;217:20200652. https://doi.org/10.1084/jem.20200652

42. Parackova Z, Zentsova I, Bloomfield M, Vrabcova P, Smetanova J, Klocperk $A$, et al. Disharmonic Inflammatory Signatures in COVID-19: Augmented Neutrophils' but Impaired Monocytes' and Dendritic Cells' Responsiveness. Cells. 2020;9:2206. https://doi.org/10.3390/cells9102206

43. Wang J, Li Q, Yin Y, Zhang Y, Cao Y, Lin X, et al. Excessive Neutrophils and Neutrophil Extracellular Traps in COVID-19. Front Immunol. 2020;11:2063. https://doi.org/10.3389/ fimmu.2020.02063

44. Huang H, Wan X, Bai Y, Bian J, Xiong J, Xu Y, et al. Preoperative neutrophil-lymphocyte and platelet-lymphocyte ratios as independent predictors of T stages in hilar cholangiocarcinoma. Cancer Manag Res. 2019;11:5157-62. https://doi. org/10.2147/CMAR.S192532

45. Şaşkın H, Düzyol Ç, Özcan KS, Aksoy R, Idiz M. Preoperative platelet to lymphocyte ratio is associated with early morbidity and mortality after coronary artery bypass grafting. Heart Surg Forum. 2015;18:E255-62. https://doi.org/10.1532/ hsf.1341

46. Kaplan M, Ates I, Oztas E, Yuksel M, Akpinar MY, Coskun O, et al. A new marker to determine prognosis of acute pancreatitis: PLR and NLR combination. J Med Biochem. 2018;37:2130. https://doi.org/10.1515/jomb-2017-0039

47. Tagawa T, Anarku M, Morodomi Y, Takenaka T, Okamoto T, Takenoyama $M$, et al. Clinical role of a new prognostic score using platelet-to-lymphocyte ratio in patients with malignant pleural mesothelioma undergoing extrapleural pneumonectomy. J Thorac Dis. 2015;7:1898-1906.

48. Zhang B, Zhou X, Zhu C, Song Y, Feng F, Qiu Y, et al. Immune Phenotyping Based on the Neutrophil-to-Lymphocyte Ratio and Ig G Level Predicts Disease Severity and Outcome for Patients With COVID-19. Front Mol Biosci. 2020;7:157. https:// doi.org/10.3389/fmolb.2020.00157

49. Chan AS, Routa A. Use of Neutrophil-to-Lymphocyte and Platelet-to-Lymphocyte Ratios in COVID-19. J Clin Med Res. 2020;12:448-53. https://doi.org/10.14740/jocmr4240

50. Yang AP, Liu JP, Tao WQ, Li HM. The diagnostic and predictive role of NLR, $d-N L R$ and PLR in COVID-19 patients. Int Immunopharmacol. 2020;84:106504. https://doi.org/10.1016/j. intimp.2020.106504

51. Jin YH, Cai L, Cheng ZS, Cheng H, Deng T, Fan Y-P, et al. A rapid advice guideline for the diagnosis and treatment of 2019 novel coronavirus (2019-nCoV) infected pneumonia (standard version). Mil Med Res. 2020;7:4. https://doi. org/10.1186/s40779-020-0233-6

52. Ye W, Chen G, Li X, Lan X, Ji C, Hou M, et al. Dynamic changes of $D$-dimer and neutrophil-lymphocyte count ratio as prognostic biomarkers in COVID-19. Respir Res. 2020;21:169. https://doi.org/10.1186/s12931-020-01428-7

53. Celikbilek M, Dogan S, Ozbakır O, Zararsiz G, Kücük $H$, Gürsoy $S$, et al. Neutrophil-lymphocyte ratio as a predictor of disease severity in ulcerative colitis. J Clin Lab Anal. 2013;27:72-6. https://doi.org/10.1002/jcla.21564 
54. Qu R, Ling Y, Zhang YH, Wei LY, Chen X, Li X-M, et al. Plateletto-lymphocyte ratio is associated with prognosis in patients with coronavirus disease-19. J Med Virol. 2020;92:1533-41. https://doi.org/10.1002/jmv.25767

55. Lu G, Wang J. Dynamic changes in routine blood parameters of a severe COVID-19 case. Clin Chim Acta. 2020;508:98102. https://doi.org/10.1016/j.cca.2020.04.034

56. Xue G, Gan X, Wu Z, Xie D, Xiong Y, Hua L, et al. Novel serological biomarkers for inflammation in predicting disease severity in patients with COVID-19. Int Immunopharmacol. 2020;89:107065. https://doi.org/10.1016/j.intimp.2020.107065

57. Usul E, Şan I, Bekgöz B, Şahin A. Role of hematological parameters in COVID-19 patients in the emergency room. Biomark Med. 2020;14:1207-15. https://doi.org/10.2217/bmm2020-0317

58. Bastug A, Bodur H, Erdogan S, Gokcinar D, Kazancioglu S, Kosovali $B D$, et al. Clinical and laboratory features of $C O-$ VID-19: Predictors of severe prognosis. Int Immunopharmacol. 2020;88:106950. https://doi.org/10.1016/j.intimp.2020.106950

59. Ahbap E, Sakaci T, Kara E, Sahutoglu T, Koc Y, Basturk T, et al. Neutrophil-to-lymphocyte ratio and platelet-tolymphocyte ratio in evaluation of inflammation in end-stage renal disease. Clin Nephrol. 2016;85:199-208. https://doi.org/10.5414/ CN108584

60. Hume DA, Irvine KM, Pridans C. The Mononuclear Phagocyte System: The Relationship between Monocytes and Macrophages. Trends Immunol. 2019;40:98-112. https://doi. org/10.1016/j.it.2018.11.007

61. Zhang D, Guo R, Lei L, Liu H, Wang Y, Wang Y, et al. COVID-19 infection induces readily detectable morphological and inflammation-related phenotypic changes in peripheral blood monocytes. J Leukoc Biol. 2021;109:13-22. https:// doi.org/10.1002/JLB.4HI0720-470R

62. Yilla M, Harcourt BH, Hickman CJ, McGrew M, Tamin A, Goldsmith CS, et al. SARS-coronavirus replication in human peripheral monocytes/macrophages. Virus Res. 2005;107:93101. https://doi.org/10.1016/j.virusres.2004.09.004

63. Jafarzadeh A, Chauhanc $P$, Saha B, Jafarzadeh S, Nemati $M$. Contribution of monocytes and macrophages to the local tissue inflammation and cytokine storm in $\mathrm{CO}$ VID-19: Lessons from SARS and MERS, and potential therapeutic interventions. Life Sci. 2020;257:118102. https://doi. org/10.1016/j.Ifs.2020.118102

64. Wen $W$, Su W, Tang H, Le W, Zhang $X$, Zheng $Y$, et al. Immune cell profiling of COVID-19 patients in the recovery stage by single-cell sequencing. Cell Discov. 2020;6:31. https://doi. org/10.1038/s41421-020-0168-9

65. Zhou Y, Fu B, Zheng X, Wang D, Zhao C, Qi Y, et al. Pathogenic T-cells and inflammatory monocytes incite inflammatory storms in severe COVID-19 patients. Natl Sci Rev. 2020;7:998-1002. https://doi.org/10.1093/nsr/nwaa041

66. Huang H, Wang S, Jiang T, Fan R, Zhang Z, Mu J, et al. High levels of circulating GM-CSF+CD4+ $T$ cells are predictive of poor outcomes in sepsis patients: a prospective cohort study. Cell Mol Immunol. 2019;16:602-10. https://doi. org/10.1038/s41423-018-0164-2
67. Weller PF, Spencer LA. Functions of tissue-resident eosinophils. Nat Rev Immunol. 2017;17:746-60. https://doi. org/10.1038/nri.2017.95

68. Zhang JJ, Dong $X, C a o$ YY, Yuan YD, Yang YB, Yan YQ, et al. Clinical characteristics of 140 patients infected with SARSCoV-2 in Wuhan, China. Allergy. 2020;75:1730-41. https:// doi.org/10.1111/all.14238

69. Mu T, Yi Z, Wang M, Wang J, Zhang C, Chen H, et al. Expression of eosinophil in peripheral blood of patients with COVID-19 and its clinical significance. J Clin Lab Anal. 2021;35:e23620. https://doi.org/10.1002/jcla.23620

70. Tan Y, Zhou J, Zhou Q, Hu L, Long Y. Role of eosinophils in the diagnosis and prognostic evaluation of COVID-19. J Med Virol. 2021;93:1105-10. https://doi.org/10.1002/jmv.26506

71. Zappert J. About the occurring of eosinophilic cells in human bleeding. Z Klin Med. 1893;23:227-308.

72. Bass DA, Grover WH, Lewis JC, Szejda P, DeChatelet $L R$, McCall CE. Comparison of Human Eosinophils from Normals and Patients with Eosinophilia. J Clin Invest. 1980;66:126573. https://doi.org/10.1172/JCl109978

73. Butterfield JH. Treatment of Hypereosinophilic Syndromes with Prednisone, Hydroxyurea, and Interferon. Immunol Allergy Clin North Am. 2007;27:493-518. https://doi. org/10.1016/j.iac.2007.06.003

74. Denzel A, Maus UA, Rodriguez Gomez M, Moll C, Niedermeier $M$, Winter $C$, et al. Basophils enhance immunological memory responses. Nat Immunol. 2008;9:733-42. https:// doi.org/10.1038/ni.1621

75. Karasuyama H, Mukai K, Obata K, Tsujimura Y, Wada T. Nonredundant Roles of Basophils in Immunity. Ann Rev Immunol. 2011;29:45-69. https://doi.org/10.1146/annurev-immunol-031210-101257

76. Rodriguez L, Pekkarinen PT, Lakshmikanth T, Tan Z, Consiglio CR, Pou C, et al. Systems-Level Immunomonitoring from Acute to Recovery Phase of Severe COVID-19. Cell Rep Med. 2020;1:100078. https://doi.org/10.1016/j.xcrm.2020.100078

77. Kazancioglu S, Bastug A, Ozbay OB, Kemirtlek N, Bodur $H$. The role of haematological parameters in patients with COVID-19 and influenza virus infection. Epidemiol Infect. 2020;148:e272. https://doi.org/10.1017/ S095026882000271X

78. Li T, Wang L, Wang H, Gao Y, Hu X, Li X, et al. Characteristics of laboratory indexes in COVID-19 patients with non-severe symptoms in Hefei City, China: diagnostic value in organ injuries. Eur J Clin Microbiol Infect Dis. 2020;39:2447-55. https://doi.org/10.1007/s10096-020-03967-9

79. Lucey DR, Clerici M, Shearer GM. Type 1 and type 2 cytokine dysregulation in human infectious, neoplastic, and inflammatory diseases. Clin Microbiol Rev. 1996;9:532-62. https://doi.org/10.1128/CMR.9.4.532

80. Podgorny PJ, Pratt LM, Liu Y, Dharmani-Khan P, Luider P, Auer-Grzesiak I, et al. Low Counts of B Cells, Natural Killer Cells, Monocytes, Dendritic Cells, Basophils, and Eosinophils are Associated with Postengraftment Infections after Allogeneic Hematopoietic Cell Transplantation. Biol Blood Marrow Transplant. 2016;22:37-46. https://doi.org/10.1016/j. bbmt.2015.09.003 
81. Florio G, Petraroli A, Patella V, Triggiani M, Marone G. The immunoglobulin superantigen-binding site of HIV-1 gp120 activates human basophils. AIDS. 2000;14:931-8. https:// doi.org/10.1097/00002030-200005260-00004

82. Qi JC, Stevens RL, Wadley R, Collins A, Cooley M, Naif HM, et al. IL-16 regulation of human mast cells/basophils and their susceptibility to HIV-1. J Immunol. 2002;168:4127-34. https://doi.org/10.4049/jimmunol.168.8.4127

83. Thomas T, Stefanoni D, Dzieciatkowska M, Issaian A, Nemkov $T$, Hill RC, et al. Evidence of Structural Protein Damage and Membrane Lipid Remodeling in Red Blood Cells from COVID-19 Patients. J Proteome Res. 2020;19:4455-69. https://doi.org/10.1021/acs.jproteome.0c00606

84. Mortaz E, Malkmohammad M, Jamaati $H$, Naghan PA, Hashemian SM, Tabarsi $P$, et al. Silent hypoxia: higher NO in red blood cells of COVID-19 patients. BMC Pulm Med. 2020;20:269. https://doi.org/10.1186/s12890-020-01310-8

85. Lazarian G, Quinquenel A, Bellal M, Siavellis J, Jacquy C, Re $D$, et al. Autoimmune haemolytic anaemia associated with COVID-19 infection. Br J Haematol. 2020;190:29-31. https:// doi.org/10.1111/bjh.16794

86. Berzuini A, Bianco C, Paccapelo C, Bertolini F, Gregato G, Cattaneo $A$, et al. Red cell-bound antibodies and transfusion requirements in hospitalized patients with $\mathrm{CO}-$ VID-19. Blood. 2020;136:766-8. https://doi.org/10.1182/blood.2020006695

87. Wang L, Duan Y, Zhang W, Liang J, Xu J, Zhang Y, et al. Epidemiologic and clinical characteristics of 26 cases of Covid-19 arising from patient-to-patient transmission in Liaocheng, China. Clin Epidemiol. 2020;12:387-91. https://doi. org/10.2147/CLEP.S249903

88. Huang Y, Tu M, Wang S, Chen S, Zhou W, Chen D, et al. Clinical characteristics of laboratory confirmed positive cases of SARS-CoV-2 infection in Wuhan, China: A retrospective single center analysis. Travel Med Infect Dis. 2020;36:101606. https://doi.org/10.1016/j.tmaid.2020.101606

89. Cen $Y$, Chen $X$, Shen $Y$, Zhang $X-H$, Lei $Y, X u C$, et al. Risk factors for disease progression in patients with mild to moderate coronavirus disease 2019-a multi-centre observational study. Clin Microbiol Infect. 2020;26:1242-47. https://doi. org/10.1016/j.cmi.2020.05.041

90. Cai SH, Liao W, Chen SW, Liu LL, Liu SY, Zheng ZD. Association between obesity and clinical prognosis in patients infected with SARS-CoV-2. Infect Dis Poverty. 2020;9:80. https:// doi.org/10.1186/s40249-020-00703-5

91. Taneri $P E$, Gómez-Ochoa $S A$, Llanaj $E$, Raguindin PF, Rojas $L Z$, Roa-Díaz ZM, et al. Anemia and iron metaboli- sm in COVID-19: a systematic review and meta-analysis. Eur J Epidemiol. 2020;35:763-73. https://doi.org/10.1007/ s10654-020-00678-5

92. Zhou F, Yu T, Du R, Fan G, Liu Y, Liu Z, et al. Clinical course and risk factors for mortality of adult inpatients with COVID-19 in Wuhan, China: a retrospective cohort study. Lancet. 2020;395:1054-62. https://doi.org/10.1016/ S0140-6736(20)30566-3

93. Li X, Xu S, Yu M, Wang K, Tao Y, Zhou Y, et al. Risk factors for severity and mortality in adult COVID-19 inpatients in Wuhan. J Allergy Clin Immunol. 2020;146:110-8. https:// doi.org/10.1016/j.jaci.2020.04.006

94. Bennett TD, Hayward KN, Farris RW, Ringold S, Wallace CA, Brogan TV. Very high serum ferritin levels are associated with increased mortality and critical care in pediatric patients. Pediatr Crit Care Med. 2011;12:e233-6. https:// doi.org/10.1097/PCC.0b013e31820abca8

95. Richardson S, Hirsch JS, Narasimhan M, Crawford JM, McGinn T, Davidson KW, et al. Presenting characteristics, comorbidities, and outcomes among 5700 patients hospitalized with COVID-19 in the New York City Area. JAMA. 2020;323:2052-59. https://doi.org/10.1001/ jama.2020.6775

96. Bellmann-Weiler R, Lanser L, Barket R, Rangger L, Schapfl $A$, Schaber $M$, et al. Prevalence and Predictive Value of Anemia and Dysregulated Iron Homeostasis in Patients with COVID-19 Infection. J Clin Med. 2020;9:2429. https:// doi.org/10.3390/jcm9082429

97. Channappanavar R, Perlman S. Pathogenic human coronavirus infections: causes and consequences of cytokine storm and immunopathology. Semin Immunopathol. 2017;39:529-39. https://doi.org/10.1007/s00281-0170629-x

98. Majeed A, Shajar MA. Is haemoglobin the missing link in the pathogenesis of COVID-19? Anaesth Pain Intensive Care. 2020;24:9-12. https://doi.org/10.35975/apic. v24i1.1216

99. Foy $B H$, Carlson JT, Reinertsen $E$, Padros Valls $R$, Pallares Lopez R, Palanques-Tost E, et al. Elevated RDW is Associated with Increased Mortality Risk in COVID-19. JAMA Netw Open. 2020;3:e2022058. https://doi.org/10.1001/jamanetworkopen.2020.22058

100. Wenzhong L, Hualan L. COVID-19: captures iron and generates reactive oxygen species to damage the human immune system. Autoimmunity. 2021;54:213-24. https:// doi.org/10.1080/08916934.2021.1913581 